\title{
Lymphangiogenesis in human corneal grafts that has evolved to re-transplantation
}

\author{
A linfangiogênese em enxertos corneanos \\ humanos que evoluem para retransplante
}

Karine Feitosa Ximenes ${ }^{1}$, Karla Feitosa Ximenes Vasconcelos², Fernando Queiroz Monte ${ }^{1}$

\begin{abstract}
Objective: To study human corneal buttons with lymphangiogenesis through histopathological examination, together with the grafts of their preceding and subsequent transplantations, evaluating the time intervals for successive surgeries.Methods: A descriptive, observational and longitudinal study of human corneal buttons that have lymphatic vessels, together with its preceding and subsequent transplants. Tissues were obtained from penetrating keratoplasty in the period between the years 2006 and 2013. After a medical records review in which information on the dates of the surgeries were mainly obtained, we built a survival table from which the time intervals for retransplantation were calculated. Results: Among 89 cases of corneal lymphangiogenesis, we included only those 22, which had previous or subsequent transplantations records in medical records. In cases where the probable regrafting etiology were lymphangiogenesis, alone or combined with hemangiogenesis (pre-lymphangiogenesis/lymphangiogenesis and interlymphangiogenesis groups), time intervals for retransplantation were found to be minor ( 7 and 3 months, respectively) than that found in lymphangiogenesis/post-lymphangiogenesis group that had other probable etiologies for retransplantations (11.31 months). Cases that had isolated lymphangiogenesis as probable etiology of retransplantation showed an interval time for retransplantation (3 months) lower than that found in cases in which the probable etiology was lymphangiogenesis associated with hemangiogenesis (7.80 months). Conclusion: Lymphangiogenesis, alone or combined with hemangiogenesis, was found in human corneal grafts studied that have evolved to regraft in small time intervals. This finding leads us to suggest a possible role for the lymphatic vessels in reducing the human corneal grafts survival time.
\end{abstract}

Keywords: Lymphangiogenesis; Angiogenesis; Corneal transplantation; Keratoplasty; Reoperation

\section{RESUMO}

Objetivo: Estudar botões corneanos humanos com linfangiogênese através do exame histopatológico, juntamente com os enxertos de seus transplantes anteriores e posteriores, avaliando os intervalos de tempo para sucessivas cirurgias. Métodos: Estudo descritivo, observacional, longitudinal de botões corneanos humanos com linfangiogênese, juntamente com seus transplantes anteriores e posteriores. Os tecidos foram provenientes de ceratoplastia penetrante no período compreendido entre os anos 2006 e 2013. Após revisão de prontuários em que foram obtidas principalmente as datas das cirurgias, construímos uma tábua de sobrevivência a partir da qual os intervalos de tempo para retransplante foram calculados. Resultados: Entre 89 casos de linfangiogênese corneana, foram incluídos apenas aqueles 22 que possuíam registros no prontuário de transplantes anteriores ou posteriores. Nos casos que apresentavam como provável etiologia do retransplante a linfangiogênese, isolada ou associada à hemangiogênese (grupos pré-linfangiogênese/linfangiogênese e interlinfangiogênese), foram encontrados intervalos de tempo para retransplante menores (7 e 3 meses, respectivamente) que aquele encontrado no grupo linfangiogênese/pós-linfangiogênese que apresentava outras etiologias prováveis para os retransplantes (11,31 meses). Casos que apresentavam como etiologia provável do retransplante a linfangiogênese isolada apresentaram um intervalo para retransplante ( 3 meses) ainda menor que aquele encontrado nos casos em que a etiologia provável era a linfangiogênese associada à hemangiogênese (7,80 meses). Conclusão: Linfangiogênese, isolada ou associada à hemangiogênese, foi encontrada nos enxertos corneanos humanos estudados que evoluíram para retransplante em pequenos intervalos de tempo. Esse achado nos leva a sugerir um possível papel para os vasos linfáticos na redução do tempo de sobrevida dos enxertos corneanos humanos.

Descritores: Linfangiogênese; Angiogênese; Transplante de córnea; Ceratoplastia; Reoperação

\footnotetext{
1,2 Hospital Geral de Fortaleza - Fortaleza (CE), Brasil.

Study conducted the Eye Bank of the Hospital Geral de Fortaleza - Fortaleza, CE, Brazil.

The authors declare no conflict of interests.

Received for publication 08/04/2015 - Accepted for publication 11/07/2015
} 


\section{INTRODUCTION}

$\mathbf{T}$ The transparency of the cornea is essential for good vision. Inflammatory reactions within this tissue can, however, cause destruction and scarring by interfering with its transparency and causing corneal blindness ${ }^{(1)}$. Corneal transplantation can restore sight, but it often fails when there is neovascularization, causing a quickly immune rejection ${ }^{(2)}$. Immune-mediated graft rejections remain the most common cause of graft failure after transplantation of organs and tissues ${ }^{(3)}$.

The three structural components of the immune system allowing responses to foreign tissues after transplantation are the afferent lymphatic vessels, the regional lymph nodes and the efferent blood vessels ${ }^{(4)}$. Once blood vessels provide an entry route for effector immune cells (CD4+ alloreactive Tlymphocytes, memory $\mathrm{T}$ lymphocytes), corneal lymphangiogenesis can output antigenic material and antigen presenting cells from the graft to regional lymph nodes. This can induce alloimmunization and subsequent graft rejection ${ }^{(5)}$. The normal cornea is devoid of blood vessels and lymph nodes ${ }^{(6,7)}$, which allows its unique privileged status ${ }^{(7)}$. However, inflammatory reactions, injuries or infections can cause the growth of new blood vessels (angiogenesis) and lymph nodes (lymphangiogenesis) on the cornea $^{(1,2)}$; which is closely related to the repeal of said privileged immune status ${ }^{(7,8)}$.

The relative importance of the lymphatic vessels versus blood vessels for immune reactions after transplantation is unclear. However, it is known that any transplantation of solid or vascularized organ is accompanied by hemangiogenesis and lymphangiogenesis through the edges of the wound ${ }^{(8)}$. In this context, the cornea has worked as an excellent in vivo model to study the role of lymphatic and blood vasculature in the mediation of allogeneic immune responses after transplan$\operatorname{tation}^{(9)}$. However, most studies on the importance of lymphangiogenesis in the rejection or survival of the corneal grafts have been held in murine models ${ }^{(8-14)}$.

Given the above, we aim at studying, through histopathological examination, the human corneal buttons that have lymphatic vessels along with the grafts from their previous and subsequent transplantations, assessing the time intervals required for successive surgeries. Admiting that the corneal lymphatic vessels are present in grafts that progress to re-transplantation in small time intervals may assist in identifying a possible role of lymphangiogenesis in the survival of the corneal grafts and in cases that could benefit from new strategies for the survival of the grafts as anti-lymphangiogenic.

\section{Methods}

After approval by the Research Ethics Committee of the General Hospital of Fortaleza, we examined corneal buttons from penetrating keratoplasty in the period between the years 2006 and 2013, sent for histopathological examination at the Eye Bank of the General Hospital of Fortaleza. The tissues were first sent to the Pathology department, where they were fixed in $10 \%$ neutral formalin and cut. The inclusion was made in paraffin with subsequent cuts of 2 to $5 \mathrm{im}$, and the staining was performed with hematoxylin-eosin. After preparation, the tissues were examined under light microscope by the authors.
Initially, we detected cases presenting lymphatic vessels. As we had no special means for detecting these vessels, we used routine staining. We selected only those cases which could be clearly identified as lymphatic vessel, i.e., those in which it was possible to clearly identify the endothelial cells, with no erythrocytes or leukocytes seen therein. Due to the greater difficulty in identifying the endothelium in the capillaries, they have not been included. Those lymphatic vessels which for some reason showed more pointed ends on the microscope slide did not take part in the study as well due to the possibility missinterpretation with the empty spaces found between keratocytes and stromal collagen fibers in cases of corneal edema.

The study was descriptive, observational and longitudinal of human corneal buttons with lymphangiogenesis, along with their previous and subsequent transplantations. Since the study was descriptive, we only checked the proportion of different time intervals for re-transplantation according to the groups considered. Another point to justify the use such statistics was rigor in the selection and inclusion of cases, since the stain used was not a specific detection method for lymphatic vessels, leading us to believe in the existence of a possible underreporting. In later studies using specific means of lymphatic detection, the probability statistics can be performed.

After the cases of corneal lymphangiogenesis have been selected, the medical records were reviewed in the search for information about age, sex, previous and subsequent transplantations and the etiology of these surgeries. So, we believe in this study only for the cases with records of keratoplasty previous or subsequent to the appearance of the lymphatic vessels.

By building a life table we calculated in months the time intervals to re-transplantation of certain groups and their average. To carry out these calculations we adopted two approaches. In the first one we calculate the intervals for retransplantation of three groups and we considered the lymphangiogenesis without specifying if it was associated to the presence of blood vessels. The first group (pre-lymphangiogenesis / lymphangiogenesis) was made up of transplantation intervals whose grafts of the first surgery didn't have lymphatic vessels, but which on the graft of the second keratoplasty had presented lymphangiogenesis. In the second group (interlymphangiogenesis), we had transplantation intervals whose grafts had presented lymphangiogenesis at both surgeries. Finally, on the third and last group (lymphangiogenesis / postlymphangiogenesis) were those transplantation intervals whose grafts from the first surgery presented lymphangiogenesis, but in which the presence of lymphatic vessels was not repeated in the graft of the second keratoplasty. Thus, we observed that in the first and second groups are those intervals in which the lymphangiogenesis could be considered as the etiology of retransplantation, since in them are the transplantations which had lymph vessels in the graft from the second surgery, with no other causes being presented for this second keratoplasty. Therefore, we did not consider in the calculation of these time intervals for re-transplantation (pre-lymphangiogenesis / lymphangiogenesis and inter-lymphangiogenesis groups) those cases with secondary causes (infection or perforation) other than the presence of corneal lymphangiogenesis as possible etiologies of re-transplant.

In the second approach, we specified among the intervals in which re-transplantations could has lymphangiogenesis as a 
probable etiology (pre-lymphangiogenesis / lymphangiogenesis and inter-lymphangiogenesis groups) those in which the lymphatic vessels were found isolated or associated with hemangiogenesis, thus obtaining three more intervals groups for re-transplantation (pre-lymphangiogenesis / lymphangiogenesis with lymphangiogenesis associated to hemangiogenesis, pre-lymphangiogenesis / lymphangiogenesis with isolated lymphangiogenesis and inter-lymphangiogenesis with isolated lymphangiogenesis on re-transplantation).

\section{RESULTS}

Initially, 89 tissues with corneal lymphangiogenesis were detected. After reviewing the medical records, however, iwe ncluded only the 22 cases which presented records of previous or subsequent transplantations, being 10 female patients and 12 male ones. The average age was $44.36 \pm 25.75$ (mean \pm SD).

On the life table we found the transplantations performed in all cases studied. We observed that we have 16 cases with two transplantations, 4 cases with three transplantations and 1 case with transplantation. For a more detailed example, we see that a case like 7 presented transplantation with lymphangiogenesis, one in which there was the recurrence of lymphatic vessels with an interval of three months for the first, and other one postlymphangiogenesis with one month of interval to the second one, totaling three transplantations. On the other hand, a case like 10 showed a pre-lymphangiogenesis transplantation and another one with lymphangiogenesis held seventeen months after the first one, totaling two transplantations. We emphasize that the number of cases in the life table ( 21 cases) is lower than the sample (22 cases), because case 7 presented lymphangiogenesis in the re-transplantation.

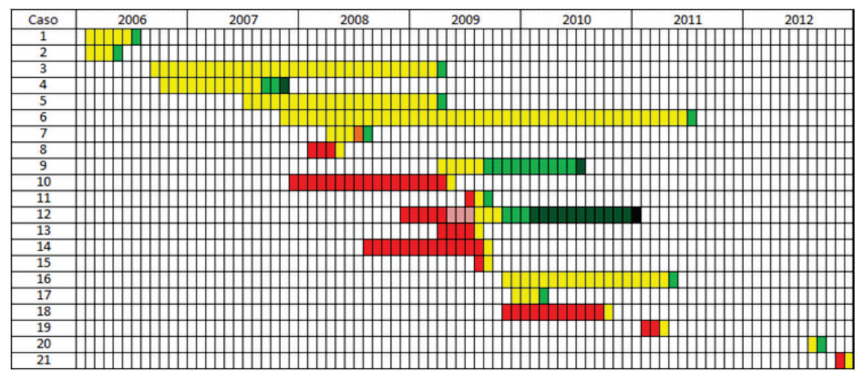

Life Table

1st transplantation pre-lymphangiogenesis 2nd transplantation pre-lymphangiogenesis 1st transplantation with lymphangiogenesis Inter-lymphangiogenesis transplantation 1st transplantation prost-lymphangiogenesis 2nd transplantation prost-lymphangiogenesis 3rd transplantation prost-lymphangiogenesis 1-month interval

Cases 11, 18, 21: Transplantation with lymphangiogenesis having infectious keratitis as etiology; Case 15: Transplantation with lymphangiogenesis having perforation as etiology.

The intervals for re-transplantation of pre-lymphangiogenesis /lymphangiogenesis, inter-lymphangiogenesis and lymphangiogenesis / post-lymphangiogenesis groups can be seen on table 1 . The greater of those intervals was the one found in the lymphangiogenesis / post-lymphangiogenesis group (11.31 months), followed by the pre-lymphangiogenesis / lymphangiogenesis (7.00 months) and inter-lymphangiogenesis (3.00 months) groups. We noted that the intervals of pre-lymphangiogenesis / lymphangiogenesis and inter-lymphangiogenesis groups, where the presence of lymphatic vessels may be considered as the etiology of re-transplantation, were even smaller than the one found in the total sample considered in this calculation approach (20 time intervals for re-transplantation with an average interval of 9.60 months). Note that we did not consider in the calculations of the intervals for re-transplantation of the prelymphangiogenesis / lymphangiogenesis group cases 11, 15, 18 and 21 , because they presented as the transplantation etiology secondary causes (infectious keratitis or perforation) other than the presence of lymphangiogenesis, as shown in the legend of the life table.

\section{Table 1}

Intervals for re-transplantation pre-lymphangiogenesis / lymphangiogenesis, inter-lymphangiogenesis and lymphangiogenesis / post-lymphangiogenesis

\begin{tabular}{lcc}
\hline \multicolumn{1}{c}{ Groups } & Number of cases & Intervals (months) \\
\hline $\begin{array}{l}\text { Pre-lymphangiogenesis / } \\
\text { lymphangiogenesis }\end{array}$ & 6 & 7.00 \\
Inter-lymphangiogenesis & 1 & 3.00 \\
Lymphangiogenesis / & & \\
post-lymphangiogenesis & 13 & 11.31 \\
Total & $\mathbf{2 0}$ & $\mathbf{9 . 6 0}$
\end{tabular}

The number of cases is lower than the sample, because the number of cases refers to the nunber of time intervals for re-transplantation calculated for each group. The intervals (months) refer to the mean intervals in each group.

In table 2, we considered only those cases that could present lymphangiogenesis as a probable etiology of re-transplantation, having a separation between those who presented hemangiogenesis associated to lymphangiogenesis or lymphangiogenesis isolated. Here, we noted that the smallest

Table 2

Intervals for re-transplantation which may have lymphangiogenesis + hemangiogenesis or isolated lymphangiogenesis as etiology

\begin{tabular}{lcc}
\hline \multicolumn{1}{c}{ Groups } & \multicolumn{1}{c}{ Number of cases } & Intervals (months) \\
\hline $\begin{array}{l}\text { Pre-lymphangiogenesis / } \\
\text { lymphangiogenesis } \\
\text { (lymphangiogenesis }+ \\
\text { hemangiogenesis) }\end{array}$ & 5 & 7.80 \\
$\begin{array}{l}\text { Pre-lymphangiogenesis / } \\
\text { lymphangiogenesis } \\
\text { (isolated lymphangiogenesis) }\end{array}$ & 1 & 3.00 \\
$\begin{array}{l}\text { Inter-lymphangiogenesis } \\
\text { (isolated lymphangiogenesis } \\
\text { in re-transplantation) }\end{array}$ & 1 & 3.00 \\
Total & $\mathbf{7}$ & \\
\hline
\end{tabular}

The number of cases refers to the nunber of time intervals for retransplantation calculated for each group. The intervals (months) refer to the mean intervals in each group. 
intervals for re-transplantation were those found in the cases that presented isolated lymphangiogenesis (3 months), whether in cases of the pre-lymphangiogenesis / lymphangiogenesis group or the inter-lymphangiogenesis group. The re-transplantation of the pre-lymphangiogenesis / lymphangiogenesis group having lymphatic vessels associated to blood vessels, in turn, have occurred with a higher average interval both for those who had isolated lymphangiogenesis ( 3 months) and for the total sample considered in this calculation approach ( 7 intervals for retransplantation with an average interval of 6.43 months).

\section{Discussion}

We performed a histopathological study of human corneal grafts with the presence of lymphatic vessels, considering in this study only the cases that presented records of previous and/or subsequent transplantations. Among 89 corneal buttons with lymphangiogenesis, we found 22 cases presenting records of these surgeries in the medical record of the Eye Bank, which corresponded to $24.72 \%$ of the initial sample, demonstrating the importance of the presence of lymphatic vessels in corneal grafts that evolve to re-transplantation. We emphasize that the size of the sample studied $(\mathrm{n}=22$ cases $)$ corresponding to about a quarter of the initial sample ( $\mathrm{n}=89$ cases) is considerable; however, it could be greater considering that we used only the records of tissues sent for histopathological examination to the Eye Bank of the General Hospital of Fortaleza, which is the routine performed only in cases of emergency. The patients could also have had elective transplantations and/or in other States, which was not taken into account in the study, with a hypoestimated number of cases that we consider quite high.

In the first approach used to calculate the time intervals for re-transplantation we found the smallest intervals in the 7 cases in which the lymphangiogenesis could be considered as the etiology of re-transplantation (pre-lymphangiogenesis / lymphangiogenesis and inter-lymphangiogenesis groups), being them 7 and 3 months, respectively. In this case, as we considered the lymphangiogenesis without specifying whether or not associated to hemangiogenesis, we could suggest the role of lymphatic vessels isolated or associated to the presence of blood vessels in the survival time of the corneal grafts. By observing table 2, however, we see that among these 7 patients, 5 presented lymphangiogenesis associated to hemangiogenesis, demonstrating that at this moment the role of the presence of lymphatic vessels associated to blood vessels is mainly suggested in the survival of corneal grafts. As previously mentioned, most studies on the importance of lymphangiogenesis in the rejection or survival of corneal grafts have been performed in murine models ${ }^{(8-14)}$. Some of these murine studies are according to our findings showing the role of hemangiogenesis and lymphangiogenesis in the rejection or survival of corneal grafts $^{(10,11)}$. Cursiefen et al. showed that after keratoplasty with avascular recipient bed (also called normal risk keratoplasty) there are competing hemangiogenesis and lymphangiogenesis dependent of the vascular endothelial growth factor A (VEGFA) within the recipient reader; and that inhibition of these afferent and efferent arms of the immune response after such transplantation promotes the long-term survival of the $\operatorname{graft}^{(10)}$. Hos et al. showed that tyrosine kinase inhibitors blocking the receptors of vascular endothelial growth factors (VEGF) are potent inhibitors not only of the inflammatory hemangiogenesis, but also of lymphangiogenesis in vivo; and that these inhibitors seem to be able to retain the formation of afferent and efferent arms of the immune reflex arc, thus being able to promote the survival of the grafts after corneal transplantation ${ }^{(11)}$. We emphasize, however, that our study was conducted in human corneas, and there are few studies like ours and the one of Zheng et al. showing that the survival time of human corneal grafts may be related to both lymphangiogenesis and hemangiogenesis ${ }^{(15)}$.

In the seconde approach used to calculate the time intervals for re-transplantation we found the smallest intervals in the cases in which the isolated lymphangiogenesis could be considered as the etiology of re-transplantation (pre-lymphangiogenesis / lymphangiogenesis with isolated lymphangiogenesis and interlymphangiogenesis with isolated lymphangiogenesis in the retransplantation groups), being them equals to 3 months in both groups. At this point, only the seven cases that could have lymphangiogenesis as probable etiology of re-transplantation were considered, but now specifying the cases in which the lymphatic vessels were found isolated or associated to hemangiogenesis, which leads us to suggest the role of the presence of isolated lymphatic vessels in the survival of corneal grafts. Here, we found that transplantation with isolated lymphangiogenesis showed a lower survival time (3 months) than those presenting lymphangiogenesis associated with hemangiogenesis (7.8 months). Comparing the results in table 1 to those of table 2 we can see that the only interlymphangiogenesis transplantation of table 1 is the same as the one presented as inter-lymphangiogenesis with isolated lymphangiogenesis on re-transplantation in table 2 , with an interval of re-transplantation equal to 3 months, which was the lowest interval found in both approaches performed during calculation. In order to explain this small interval found in both calculation approaches we suggest two explanations. The first is the possibility of lymphangiogenesis to be repeated in the retransplantation proving to be one more risk factor for graft failure compared to its first appearance. The second one is the possibility of isolated lymphangiogenesis being associated to a smaller graft survival time than lymphangiogenesis associated to hemangiogenesis. We can not say for sure which of the hypotheses would be stronger. The fact that the other case of isolated lymphangiogenesis (pre-lymphangiogenesis / lymphangiogenesis with isolated lymphangiogenesis) has a retransplantation interval ( 3 months) similar to the case mentioned above (inter-lymphangiogenesis with lymphangiogenesis isolated in the re-transplantation) reinforces the second hypothesis. The study of Zheng et al. showed a shorter survival time in the cases of re-transplantation in which lymphangiogenesis associated to hemangiogenesis was repeated, which reinforces the first hypothesis ${ }^{(15)}$. We also believe that the greatest time interval for re-transplantation found in the cases presenting hemangiogenesis associated to lymphangiogenesis compared to those with isolated lymphangiogenesis should be further studied to assess whether this is a biological occurrence due to probable less severe conditions of edema.

In the context of the isolated role of lymphatic vessels in the survival or rejection of corneal grafts, we found no studies that, like ours, demonstrate the presence of cases of lymphangiogenesis independent from hemangiogenesis possibly associated to the decreased survival of transplantations. One 
possible explanation for not having found such a study would be the fact that most of the studies mention a close relation between the hemangiogenesis processes and lymphangiogenesis $^{(5,10,16,17)}$, and few are those like Nakao et al. and Chang et al., who mention the possibility of occurrence of lymphatic vessels without the presence of blood vessels ${ }^{(18,19)}$. However, to our interpretation Dietrich et al. seem to have emphasized the role of isolated lymphangiogenesis whem studying the relative importance of the lymphatic vessels in relation to the blood vessels in mediating immune responses after transplantation, and therefore they used the selective and specific pre-operative inhibition of lymphangiogenesis ${ }^{(8)}$. Zheng et al. also seem somehow to have separated the roles of lymphangiogenesis, hemangiogenesis and the association of hemangiogenesis + lymphangiogenesis in the survival time of the grafts through statistical analysis $^{(15)}$.

Many studies have also mentioned that antilymphangiogenic strategies may improve survival of solid organ transplantation $^{(8,9)}$ or cornea ${ }^{(6,8,9,11,14,20,21)}$. It has been shown that the combined inhibition of hemangiogenesis and lymphangiogenesis by the molecular ligand of vascular endothelial growth factor $\left(\mathrm{VEGF} \operatorname{Trap}_{\mathrm{R} 1 \mathrm{R} 2}\right)^{(10)}$, tyrosine kinase inhibitors blocking the vascular endothelial growth factors ${ }^{(11)}$, bevacizumab $^{(14)}$ and sunitinib ${ }^{(21)}$ can increase the survival of corneal grafts. New approaches such as signaling inhibition of receptor 3 of VEGF (VEGFR-3)(22) or the use of molecules against á5â1 integrin of the lymphatic endothelium ${ }^{(23)}$ have also been reported to selectively inhibit lymphangiogenesis during corneal inflammatory neovascularization in a murine model. Thus, by recognizing the need for strategies to promote graft survival without compromising the receptor's health ${ }^{(3)}$ and the possible future therapeutic potential of corneal lymphangiogenesis we emphasize the growing importance of studies demonstrating its role, either isolated or associated to hemangiogenesis in the survival time of corneal transplantation.

Finally, we emphasize that the facts that we had no possibility of giving firm conclusions have been problematized, so that future research is centered on these points. Most of the cases studied corresponded to emergency keratoplasty, and we know that in these situations there are many factors other than the presence of lymphangiogenesis that may influence the survival of the graft. Possible secondary causes, however, were excluded in the methodology used. In some groups, we also found a small number of cases after the sub-classification of the original group. These subdivisions were, however, required to demonstrate the role of lymphangiogenesis separately from angiogenesis. The only inter-lymphangiogenesis transplantation also needed to be recorded as a theoretically possible fact and observation of reality. Due to the corneal lymphangiogenesis in humans be a subject of few studies in Brazil and abroad, we believe that even a so-called small number of cases in some groups have great relevance. Our goal was not to try and demonstrate a correlation between the presence of lymphatic vessels and the reduced survival time of human corneal grafts, but only to demonstrate the presence of lymphatic vessels in human corneal grafts developing to re-transplantation in a short time interval. Once we conducted a descriptive study, correlation tests would exceed our limits. We hope that our findings are a stimulus for further studies with different methodologies and a larger number of cases that will confirm a possible role of lymphangiogenesis in human corneal graft survival.

\section{CONCLUSION}

We have demonstrated by means of histopathological examination findings that lymphangiogenesis isolated or associated to hemangiogenesis was found in human corneal grafts studied that evolved to re-transplantation in a small time interval. This finding led us to suggest a possible role for the lymphatic vessels in the decreased survival time of human corneal grafts, confirming the experimental findings in animals (murines).

Recognizing that the presence of lymphatic vessels in human corneal grafts, either isolated or associated to blood vessels, may play a role in the risk of failure thereof; it should assist in identifying cases that would benefit from the use of new strategies to improve the survival of corneal transplantation as anti-lymphangiogenic.

\section{ReFERENCES}

1. Cursiefen C. Immune privilege and angiogenic privilege of the cornea. Chem Immunol Allergy. 2007;92:50-7.

2. Skobe M, Dana R. Blocking the path of lymphatics vessels. Nat Med. 2009;15(9): 993-4.

3. Lechler RI, Sykes M, Thomson AW, Turka LA. Organ transplantation-how much of the promise has been realized? Nat Med. 2005;11(6):605-13.

4. Kaplan HJ, Streilein JW, Stevens TR. Transplantation immunology of the anterior chamber of the eye. II. Immune response to allogeneic cells. J Immunol. 1975;115(3):805-10.

5. Ling SQ, Liu C, Li WH, Xu JG, Kuang WH. Corneal lymphangiogenesis correlates closely with hemangiogenesis after keratoplasty. Int J Ophthalmol. 2010;3(1):76-9.

6. Cursiefen C, Chen L, Dana MR, Streilein JW. Corneal lymphangiogenesis: evidence, mechanisms, and implications for corneal transplant immunology. Cornea. 2003;22(3):273-81.

7. Patel SP, Dana R. Corneal lymphangiogenesis: implications in immunity. Semin Ophthalmol. 2009;24(3):135-8.

8. Dietrich T, Bock F, Yuen D, Hos D, Bachmann BO, Zahn G, et al. Cutting edge: lymphatic vessels, not blood vessels, primarily mediate immune rejections after transplantation. J Immunol. 2010;184(2):535-9.

9. Hos D, Cursiefen C. Lymphatic vessels in the development of tissue and organ rejection. Adv Anat Embryol Cell Biol. 2014;214:119-41.

10. Cursiefen C, Cao J, Chen L, Liu Y, Maruyama K, Jackson D, et al. Inhibition of hemangiogenesis and lymphangiogenesis after normal-risk corneal transplantation by neutralizing VEGF promotes graft survival. Invest Ophthalmol Vis Sci. 2004;45(8):2666-73.

11. Hos D, Bock F, Dietrich T, Onderka J, Kruse FE, Thierauch KH, et al. Inflammatory corneal (lymph)angiogenesis is blocked by VEGFR-tyrosina kinase inhibitor ZK 261991, resulting in improved graft survival after corneal transplantation. Invest Ophthalmol Vis Sci. 2008;49(5):1836-42.

12. Ling S, Qi C, Li W, Xu J, Kuang W. Crucial role of corneal lymphangiogenesis for allograft rejection in alkali-burned cornea bed. Clin Experiment Ophthalmol. 2009;37(9):874-83.

13. Hos D, Bachmann B, Bock F, Onderka J, Cursiefen C. Age-related changes in murine limbal lymphatic vessels and corneal lymphangiogenesis. Exp Eye Res. 2008;87(5):427-32.

14. Bock F, Onderka J, Dietrich T, Bachmann B, Kruse FE, Paschke $\mathrm{M}$, et al. Bevacizumab as a potent inhibitor of inflammatory corneal angiogenesis and lymphangiogenesis. Invest Ophthalmol Vis Sci. 2007;48(6):2545-52. 
15. Zheng Y, Lin H, Ling S. Clinicopathological correlation analysis of (lymph) angiogenesis and corneal graft rejection. Mol Vis. 2011;17:1694-700.

16. Regina M, Zimmerman R, Malik G, Gausas R. Lymphangiogenesis concurrent with haemangiogenesis in the human cornea. Clin Experiment Ophthalmol. 2007;35(6):541-4.

17. Cursiefen C, Maruyama K, Jackson DG, Streilein JW, Kruse FE. Time course of angiogenesis and lymphangiogenesis after brief corneal inflammation, Cornea. 2006;25(4):443-7.

18. Nakao S, Maruyama K, Zandi S, Melhorn MI, Taher M, Noda K, et al. Lymphangiogenesis and angiogenesis: concurrence and/or dependence? Studies in inbred mouse strains. FASEB J. 2010;24(2):504-13.

19. Chang LK, Garcia-Cardena G, Farnebo F, Fannon M, Chen EJ, Butterfield C, et al. Dose-dependent response of FGF-2 for lymphangiogenesis. Proc Natl Acad Sci USA. 2004;101(32): 11658-63.

20. Cursiefen C, Seitz B, Dana MR, Streilein JW. Angiogenesis and lymphangiogenesis in the cornea. Pathogenesis, clinical implications and treatment options. Ophthalmologue. 2003; 100(4): 292-9.
21. Detry B, Blacher S, Erpicum C, Paupert J, Maertens L, Maillard C, et al. Sunitinib inhibits inflammatory corneal lymphangiogenesis. Invest Ophthalmol Vis Sci. 2013;54(5):3082-93.

22. Bock F, Onderka J, Dietrich T, Bachmann B, Pytowski B, Cursiefen C. Blockade of VEGFR3-signalling specifically inhibits lymphangiogenesis in inflammatory corneal neovascularisation. Graefes Arch Clin Exp Ophthalmol. 2008;246(1):115-9.

23. Dietrich T, Onderka J, Bock F, Kruse FE, Vossmeyer D, Stragies $\mathrm{R}$, et al. Inhibition of inflammatory lymphangiogenesis by integrin alpha5 blockade. Am J Pathol. 2007;171(1):361-72.

\section{Corresponding author:}

Author: Karine Feitosa Ximenes

Street: Andrade Furtado, 150- apto 1501- Neighborhood: CocóFortaleza - Ceará

ZIP Code: 60192-070

Phone No.: (85) 3262-6781 / (85) 9673-3132

E-mail: karinefx@gmail.com 